\title{
ALGORITHM OF CONTROLLING AN ADAPTIVE HYDRAULIC CIRCUIT FOR MOBILE MACHINES
}

\author{
Leonid Kozlov ${ }^{1}$, Yurii Buriennikov ${ }^{1}$, Oana Rusu ${ }^{2}$, Volodymyr Pyliavets ${ }^{1}$, $\operatorname{Vadym~Kovalchuk~}^{1}$, \\ Oleksandr Petrov ${ }^{1}$, Ioan Rusu ${ }^{2}$ \\ ${ }^{1}$ Vinnytsia National Technical University, 95 Khmelnytske Shose St., Vinnytsia, 21021, Ukraine \\ 2"'Gheorghe Asachi" Technical University, 41 Dimitrie Mangeron Blvd., Iași, 700050, Romania
}

Corresponding author: Oana Rusu, oana.rusu@academic.tuiasi.ro

\begin{abstract}
Hydraulic systems based on adjustable pumps, proportional electrohydraulic equipment and controllers are used in mobile machines. The authors propose a new scheme of the hydraulic system for mobile machines, which provides the auger drilling operation. A number of studies have shown that a certain ratio should be maintained between the frequency of auger rotation and its feed during operation, where the productivity of soil disruption should not exceed the productivity of transporting loose soil from the drilling zone. Ensuring the required ratio between the speed of the auger rotation and its feed is implemented by a controller that works according to a certain algorithm. A nonlinear mathematical model of the hydraulic system was developed to create the algorithm for controller operation and setting. The equations of the mathematical model are solved in the MATLAB-Simulink environment by the Rosenbrock method. As a result of solving the equations for the mathematical model, the dependences of variables describing the state of the hydraulic system on time are obtained. The values of the controller settings are determined at which the hydraulic system works steadily, the error of flow rate stabilization, the time for pressure adjustment and readjustment does not exceed the allowable values. The algorithm for controlling the auger feed value is formed. This algorithm provides the necessary ratio between the auger feed and speed, as well as reducing the feed rate in the case of soil hardness increases. This creates the conditions for uninterrupted pit drilling at full depth and protection of the hydraulic system from overload.
\end{abstract}

Key words: mobile machine, controller, adaptive hydraulic circuit, mathematical model, controlling algorithm.

\section{INTRODUCTION}

Mobile machines with hydraulic drive and replaceable actuating elements are widely used in industry, construction, agriculture and transport [1-4]. Such machines are efficiently operated during all seasons of the year and perform various operations due to the use of loading buckets, hydraulic hammers, excavator, drilling and crane equipment. The hydraulic systems of these machines must provide highly economical operation in a wide range of load changes on the actuating elements and allow the regulation of speed modes with minimal power loss. In addition, the operation of a hydraulic system must be stable with the simultaneous inclusion of two hydraulic motors, the value of pressure readjustment should not exceed $30 \%$, and the error of flow rate stabilization of the hydraulic motors should be less than $10 \%$. Such hydraulic systems are built on the basis of adjustable pumps, proportional electrohydraulic equipment, sensors and controllers. The programmable controllers available in the hydraulic systems of mobile machines create broad options for adapting the operation modes of hydraulic systems to changes in external operating conditions and loads. As a rule, controllers implement different types of feedback, which allows to provide the necessary static and dynamic characteristics of hydraulic systems. The issue of effective correction of cross-links that occur during the simultaneous operation of several circuits is very interesting to research $[1,2,4-6]$.

The efficiency increase of hydraulic systems with the last generation machines is provided by means of adapting high-speed modes of movement of actuating elements to change of external loadings at simultaneous work of two hydraulic motors [7]. So, during the operation of drilling pits with the auger, it is necessary to coordinate the auger feed value with the frequency of auger rotation. It provides necessary productivity in transporting loosened rock from a drilling zone, and accordingly continuity of machine operation process. In the case when the auger feed exceeds the critical value, the disruption of rock in the drilling zone is more intense than the transportation of the destroyed rock to the surface, which leads to the formation of the auger zone of excessively compacted soil. At the same time the drilling process must be stopped, the auger should be lifted from the pit and forcibly cleaned of compacted soil. This fact significantly reduces the drilling process productivity $[8,9]$. 
The task of creating an algorithm for controlling the hydraulic system of a mobile machine which coordinates the ratio of feed and the auger rotation speed during drilling is topical to ensure the continuity of the drilling process and increase productivity. Creation of algorithm for controlling an adaptive hydraulic system should be based on researches of static and dynamic characteristics. This is due to the fact that the cross-link, which is implemented by the controller to coordinate the speeds of hydraulic motors has a negative impact on the accuracy of adjustment, operational speed and re-adjustment in the hydraulic system. When developing a control algorithm, the setting of the controller parameters should be chosen such that the requirements for the hydraulic system are met. This can be achieved by developing a mathematical model of an adaptive hydraulic system and calculating static and dynamic characteristics and comparing them with the allowable indicators of control accuracy, operational speed and re-adjustment. It is also necessary to ensure control over the maximum pressure values in the hydraulic system in order to protect hydraulic equipment and pipelines from disruption.

\section{DEVELOPMENT OF CONTROL ALGORITHM FOR AN ADAPTIVE HYDRAULIC SYSTEM}

In Figure 1, the scheme of the adaptive hydraulic system developed by the authors is presented [10]. The adaptive hydraulic system includes: adjustable pumps 1 and 2, distributors 3,4 , hydraulic cylinder 5 , hydraulic motor 6 , adjustable throttles 7,16 , differential pressure valves 8,17 , controller 9 , amplifiers 10,11 , pressure sensor 12 and tank 19 . The hydraulic cylinder 5 , which moves the handle 14 is mounted on the boom 13 of the excavator. On the handle 14, the hydraulic motor 6 is installed, which actuates the auger 15 . The adaptive hydraulic system operates as follows. The adjustable pump 1 supplies the working fluid to the hydraulic motor 6 through the adjustable throttle 7 and the distributor 3 . The distributor 3 with manual control provides stop, start and reverse of the hydraulic motor 6. The adjustable throttle 7 with electromagnetic control from the controller 9 provides a change in the feed value $Q_{n 1}$, supplied by the pump 1 to the hydraulic motor 6 . By changing the value of the area $f_{x 1}$ of the working window of the adjustable throttle 7 , it is possible to adjust the rotation speed $\omega_{m}$ of the shaft of the hydraulic motor 6 . The sensor 12 measures the pressure at the inlet of the hydraulic motor 6 and transmits the corresponding signal to the controller 9 . The adjustable pump 2 supplies the working fluid to the hydraulic cylinder 5 through the adjustable throttle 16 and the distributor 4 . The distributor 4 provides stop, start and reverse of the hydraulic cylinder 5. The adjustable throttle 16 with electromagnetic control from the controller 9 provides a feed change $Q_{n 2}$, supplied from the pump 2 to the hydraulic cylinder 5 . This enables to control the travel speed $v_{s n}$ of auger 15. Based on the signal from the sensor 12, the controller 9 generates an algorithm for controlling the adjustable throttles 7, 16, which provides the optimal ratio between the rotation speed $\omega_{m}$ of the auger 15 and its feed speed $v_{s n}$.

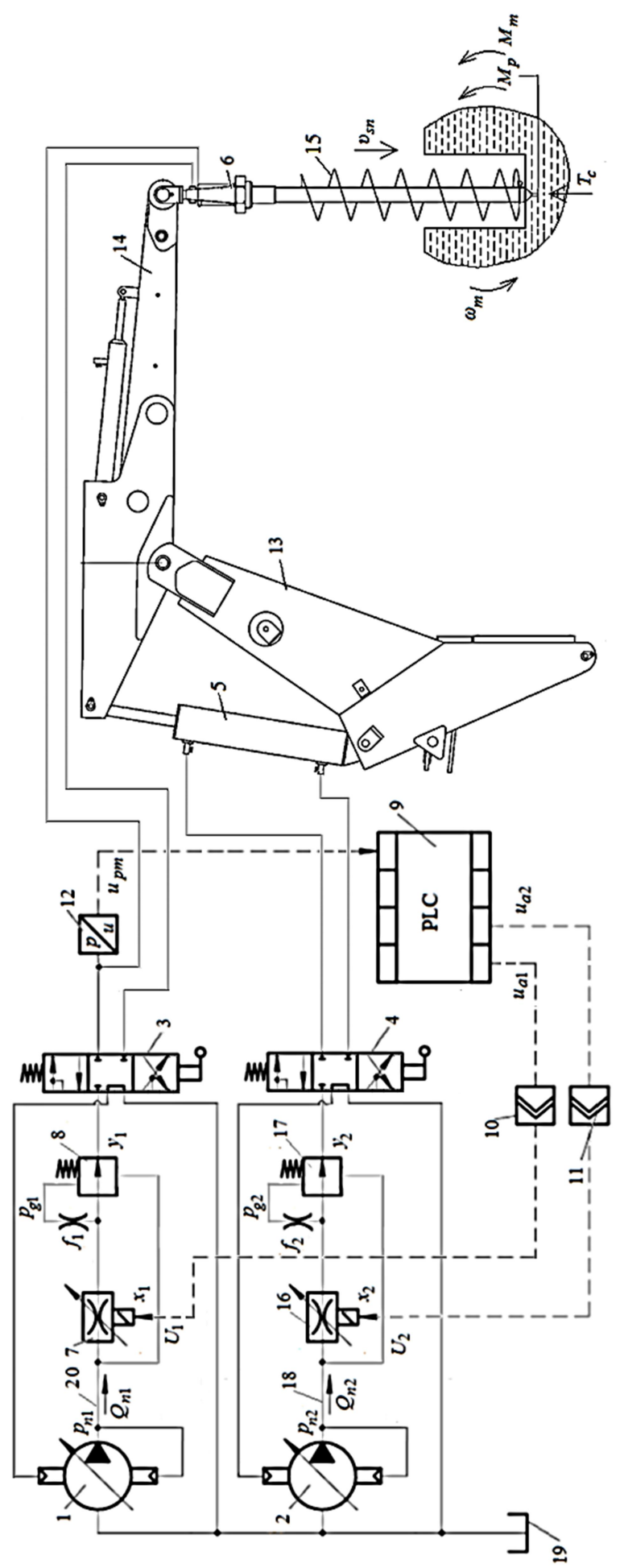

Fig. 1. Scheme of adaptive hydraulic system 
The hydraulic system uses an adaptive regulator (Figure 2), which has the unit 1 for switching modes, units 2, 3 for adjusting the flow rates for hydraulic motors, mode switch 4, signal delay units 5,6 , unit 7 for forming the pattern of the ratio change between the flow rates to hydraulic motors, unit 8 for forming the transfer coefficient of the adjusting component, unit 9 for forming the derivative. The adaptive regulator processes signals $U_{h 1}, U_{h 2}, U_{p m 2} U_{p c}$ from position sensors of distributing valves and pressure according to control algorithm and generates signals by means of which the elements of adaptive hydraulic system are controlled. Using the signals $U_{a 1}, U_{a 2}$, the ratio of the rotation speed $\omega_{m}$ of the auger 15 and its feed $v_{s n}$ is adjusted (Figure 1). The adaptive regulator provides adjustment of the cross-connection signal between circuits which provide auger rotation and feed in order to improve the dynamic characteristics of the hydraulic system. The adaptive controller provides for possible adjustment of the parameter $k_{p}$ - the transfer ratio of the adjustment component and $\Delta T_{0}$ - the time delay of the cross-connection signal.

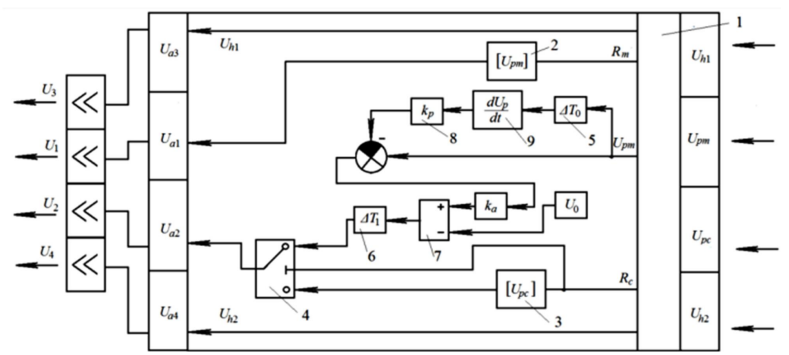

Fig. 2. Scheme of adaptive regulator
A mathematical model was developed for the presented adaptive hydraulic system. A non-linear mathematical model is built up under the following simplifications and assumptions [11-15]. Parameters of the hydraulic system elements are considered as concentrated, the working fluid temperature remains unchanged in transient operating modes, the flow rate coefficients for throttle and spool elements are considered constant, there are no cavitation modes in the operation of the hydraulic system, the volumes of hydraulic lines and chambers of the hydraulic cylinder do not change during the transition process, the pressure losses in hydraulic lines and channels of hydraulic equipment, except for the distributor, are not taken into account. The controller is modelled as an analogue regulator. The pressures in the rod chamber of the cylinder and on the drain of the hydraulic motor are considered constant values, the pressure in the circuit of the hydraulic cylinder does not exceed the pressure in the circuit of the hydraulic motor. The flow of working fluid between the chambers of the hydraulic cylinder is not taken into account.

The mathematical model of the adaptive hydraulic system includes the equation of continuity of flows for hydraulic lines between hydraulic units, the equation of moments acting on pump circuit plates, handles and shaft of the hydraulic motor, the equation of forces acting on pump regulators, adjustable throttles, pressure drop valves, the equation of voltage drop for control lines.

$$
\begin{aligned}
& \frac{\pi d_{7}^{2}}{4} d_{8} k n_{i} t_{g} \gamma_{i}-k_{n} p_{n i}=Q_{x i}+\mu k_{z} z_{i} \sqrt{\frac{2\left|p_{n i}-p_{0 i}\right|}{\rho}} \operatorname{sign}\left(p_{n i}-p_{0 i}\right)+\beta_{n} W_{n i} \frac{d p_{n i}}{d t} \\
& Q_{x i}=Q_{y i}+\beta_{n} W_{y i} \frac{d p_{y i}}{d t}+\mu f_{i} \sqrt{\frac{2\left|p_{y i}-p_{g i}\right|}{\rho}} \operatorname{sign}\left(p_{y i}-p_{g i}\right) \\
& Q_{y i}=Q_{v i}+\beta W_{v i} \frac{d p_{v i}}{d t} \\
& Q_{v 1}=\frac{2 \pi m q_{m}}{\eta_{1}}+\beta_{n} W_{m} \frac{d p_{m}}{d t} \\
& \mathrm{Q}_{\mathrm{v} 2}=\frac{\pi \mathrm{d}_{\mathrm{c}}^{2} \mathrm{v}_{\mathrm{sn}} \mathrm{l}_{2} \cos \alpha_{2}}{4 \mathrm{l}_{1} \cos \alpha_{1} \cos \alpha_{3}}+\beta_{\mathrm{n}} \mathrm{W}_{\mathrm{c}} \frac{\mathrm{dp} \mathrm{c}}{\mathrm{dt}} \\
& \mu f_{i} \sqrt{\frac{2\left|p_{y i}-p_{g i}\right|}{\rho}} \operatorname{sign}\left(p_{y i}-p_{g i}\right)=\beta_{n} W_{g i} \frac{d p_{g i}}{d t}+\frac{\pi d_{y i}^{2}}{4} \cdot \frac{d y_{i}}{d t}+\left(A_{y} p_{g i}+B_{y} t^{\circ}+C_{y} \varepsilon_{b}^{2}\right) \\
& \mu \mathrm{k}_{\mathrm{z}} \mathrm{z}_{\mathrm{i}} \sqrt{\frac{2\left|\mathrm{p}_{\mathrm{ni}}-\mathrm{p}_{0 \mathrm{i}}\right|}{\rho}} \operatorname{sign}\left(\mathrm{p}_{\mathrm{ni}}-\mathrm{p}_{0 \mathrm{i}}\right)=\beta_{\mathrm{p}} \mathrm{W}_{0} \frac{\mathrm{dp}_{0 \mathrm{i}}}{\mathrm{dt}}+\mu \mathrm{f}_{\mathrm{e}} \sqrt{\frac{2\left|\mathrm{p}_{0 \mathrm{i}}-\mathrm{p}_{\mathrm{ei}}\right|}{\rho}} \operatorname{sign}\left(\mathrm{p}_{0 \mathrm{i}}-\mathrm{p}_{\mathrm{ei}}\right)+\mu \mathrm{f}_{0} \sqrt{\frac{2 \mathrm{p}_{0 \mathrm{i}}}{\rho}} \\
& \mu \mathrm{f}_{\mathrm{e}} \sqrt{\frac{2\left|\mathrm{p}_{0 i}-\mathrm{p}_{\mathrm{ei}}\right|}{\rho}} \operatorname{sign}\left(\mathrm{p}_{0 \mathrm{i}}-\mathrm{p}_{\mathrm{ei}}\right)=\beta_{\mathrm{n}} \mathrm{W}_{\mathrm{e}} \frac{\mathrm{dp} \mathrm{p}_{\mathrm{ei}}}{\mathrm{dt}}-\mathrm{f}_{4} 1 \frac{\mathrm{d} \gamma_{\mathrm{i}}}{\mathrm{dt}}-\left(\mathrm{A}_{\mathrm{e}} \mathrm{p}_{\mathrm{ei}}+\mathrm{B}_{\mathrm{e}} \mathrm{t}^{\circ}+\mathrm{C}_{\mathrm{e}} \varepsilon_{\mathrm{e}}^{2}\right) \\
& \mathrm{I}_{1} \frac{\mathrm{d}^{2} \gamma_{\mathrm{i}}}{\mathrm{dt}^{2}}=\mathrm{p}_{\mathrm{ni}} \mathrm{f}_{5} \mathrm{l}-\mathrm{p}_{\mathrm{ei}} \mathrm{f}_{4} \mathrm{l}-\frac{\pi \rho v_{\mathrm{k}} \mathrm{d}_{4} \mathrm{l}_{4}}{\varepsilon_{0}} \mathrm{l}^{2} \frac{\mathrm{d} \gamma_{\mathrm{i}}}{\mathrm{dt}} \cos \gamma_{\mathrm{i}}-\frac{\pi \rho v_{\mathrm{k}} \mathrm{d}_{5} \mathrm{l}_{5}}{\varepsilon_{\mathrm{o}}} \mathrm{l}^{2} \frac{\mathrm{d} \gamma_{\mathrm{i}}}{\mathrm{dt}} \cos \gamma_{\mathrm{i}}+ \\
& +m_{0}+m_{1} Q_{n i}+m_{2} p_{n i}+m_{3} Q_{n i}^{2}+m_{4} p_{n i}^{2}+m_{5} p_{n i} Q_{n i}
\end{aligned}
$$




$$
\begin{aligned}
& \mathrm{m}_{\mathrm{pi}} \frac{\mathrm{d}^{2} \mathrm{z}_{\mathrm{i}}}{\mathrm{d \textrm {t } ^ { 2 }}}=\mathrm{p}_{\mathrm{ni}} \frac{\pi \mathrm{d}_{\mathrm{p}}^{2}}{4}-\mathrm{p}_{\mathrm{mi}} \frac{\pi \mathrm{d}_{\mathrm{p}}^{2}}{4}-\mathrm{c}_{\mathrm{z}}\left(\mathrm{H}_{\mathrm{zi}}+\mathrm{z}_{\mathrm{i}}\right)-\frac{\pi \rho v_{\mathrm{k}} \mathrm{d}_{\mathrm{p}} \mathrm{l}_{\mathrm{p}}}{\varepsilon_{\mathrm{p}}} \frac{\mathrm{dz_{i }}}{\mathrm{dt}} \\
& \mathrm{m}_{\mathrm{yi}} \frac{\mathrm{d} \mathrm{y}_{\mathrm{i}}^{2}}{\mathrm{dt}^{2}}=\mathrm{p}_{\mathrm{gi}} \frac{\pi \mathrm{d}_{\mathrm{yi}}^{2}}{4}-\mathrm{p}_{\mathrm{y} 1} \frac{\pi \mathrm{d}_{\mathrm{yi}}^{2}}{4}-c_{\mathrm{y}}\left(\mathrm{H}_{\mathrm{yi}}+\mathrm{y}_{\mathrm{i}}\right)-\left(\mathrm{A}_{\mathrm{gi}}+\mathrm{B}_{\mathrm{gi}} \mathrm{p}_{\mathrm{ni}}-\frac{\mathrm{D}_{\mathrm{gi}}}{\mathrm{y}_{\mathrm{i}}}+\frac{\mathrm{E}_{\mathrm{gi}}}{\mathrm{y}_{\mathrm{i}}^{2}}\right)-\frac{\pi \rho v_{\mathrm{k}} \mathrm{d}_{\mathrm{yi}} \mathrm{l}_{\mathrm{yi}} \frac{d \mathrm{y}_{\mathrm{i}}}{\varepsilon_{\mathrm{yi}}}}{\mathrm{dt}} \\
& I_{m} \frac{d \omega_{m}}{d t}=p_{m} q-b_{m} \omega_{m}-M_{m}-M_{p} \\
& \mathrm{I}_{\mathrm{c}} \frac{\mathrm{d}^{2} \varphi_{\mathrm{c}}}{\mathrm{dt} \mathrm{t}^{2}}=\mathrm{p}_{\mathrm{c}} \frac{\pi \mathrm{d}_{\mathrm{c}}^{2}}{4} \mathrm{l}_{1} \cos \alpha_{1}-\frac{\mathrm{T}_{\mathrm{c}} \cos \alpha_{2} \mathrm{l}_{2}}{\cos \alpha_{3}}-\pi \mathrm{d}_{\mathrm{c}}\left(\mathrm{q}_{0}+\mathrm{k}_{\mathrm{q}} \mathrm{p}_{\mathrm{c}}\right)-\pi \mathrm{d}_{\mathrm{s}}\left(\mathrm{q}_{0}+\mathrm{k}_{\mathrm{q}} \mathrm{p}_{\mathrm{p}}\right) \mathrm{l}_{1} \cos \alpha_{1}-\mathrm{M}_{\mathrm{c}} \\
& \mathrm{i}_{\mathrm{m} 1} \mathrm{k}_{\mathrm{m} 1}=\mathrm{c}_{1}\left(\mathrm{H}_{1}+\mathrm{x}_{1}\right), \quad \mathrm{i}_{\mathrm{m} 2} \mathrm{k}_{\mathrm{m} 2}=\mathrm{c}_{2}\left(\mathrm{H}_{2}+\mathrm{x}_{2}\right) \\
& \mathrm{p}_{\mathrm{m}} \mathrm{k}_{4} \mathrm{~F}_{\mathrm{n}} \mathrm{F}_{\mathrm{k}}\left(\mathrm{U}_{\mathrm{pm}}\right)=\mathrm{U}_{2} \\
& \mathrm{~F}_{\mathrm{k} 1} \mathrm{k}_{\mathrm{n}}=\mathrm{U}_{1} \\
& \mathrm{U}_{2}=\mathrm{Le} \frac{\mathrm{di}_{\mathrm{m} 2}}{\mathrm{dt}}+\mathrm{i}_{\mathrm{m} 2} \operatorname{Re} \\
& \mathrm{U}_{1}=\mathrm{Le} \frac{\mathrm{di} \mathrm{m}_{1}}{\mathrm{dt}}+\mathrm{i}_{\mathrm{m} 1} \operatorname{Re} \\
& \beta_{\mathrm{n}}=\frac{1}{\mathrm{E}_{\mathrm{p}}}+\frac{\mathrm{d}_{\mathrm{mp}}}{\delta_{\mathrm{mp}} \mathrm{E}_{\mathrm{mp}}(\mathrm{p})} \\
& \mathrm{E}_{\mathrm{p}}=\frac{1}{\beta_{\mathrm{p}}}=\mathrm{E}_{\mathrm{p} 0}=\frac{\mathrm{W}_{\mathrm{f}} / \mathrm{W}_{\mathrm{a}}+1}{\mathrm{~W}_{\mathrm{f}} / \mathrm{W}_{\mathrm{a}}+\left(\mathrm{E}_{\mathrm{p} 0} \mathrm{p}_{0}\right) / \mathrm{p}^{2}} \\
& \mathrm{Q}_{\mathrm{xi}}=\mathrm{a}_{1} \mathrm{x}_{\mathrm{i}}+\mathrm{b}_{1} \mathrm{p}_{\mathrm{yi}}+\mathrm{c}_{1} \mathrm{p}_{\mathrm{ni}}+\mathrm{d}_{1}
\end{aligned}
$$

where $\mathrm{a}_{1}=0.041, \mathrm{~b}_{1}=-1.30 \cdot 10^{-11}, \mathrm{c}_{1}=3.1 \cdot 10^{-11}, \mathrm{~d}_{1}=-2.21 \cdot 10^{-5}$,

$$
Q_{v i}=a_{2}+\frac{b_{2}}{p_{v i}}+\frac{c_{2}}{p_{v i}^{2}}+\frac{d_{2}}{p_{m}}+\frac{e_{2}}{p_{m}^{2}}
$$

where $a_{2}=7 \cdot 10^{-4}, b_{2}=-6.58 \cdot 10^{5}, c_{2}=9.09 \cdot 10^{11}, d_{2}=6.37 \cdot 10^{-5}, e_{2}=-8.4 \cdot 10^{11}$,

$$
\mathrm{Q}_{\mathrm{yi}}=\exp \left(\mathrm{a}_{3} \mathrm{y}_{\mathrm{i}}+\mathrm{b}_{3} \mathrm{p}_{\mathrm{yi}}+\mathrm{c}_{3} \mathrm{p}_{\mathrm{vi}}+\mathrm{d}_{3}\right)
$$

where $a_{3}=501, b_{3}=-4.4 \cdot 10^{-8}, c_{3}=2.9 \cdot 10^{-7}, d_{3}=-7.27$,

moment of cutting the soil during auger drilling

feeding force

$$
M_{m}=C_{1}\left(v_{s n} \frac{2 \pi}{z \omega_{m}}\right)^{c_{2}} \pi R_{c}^{2} v_{s n}
$$

$$
\mathrm{T}_{\mathrm{c}}=\mathrm{k}_{\mathrm{n}} \frac{2 \mathrm{eQ}}{\omega_{\mathrm{m}} \sqrt{\mathrm{R}_{1}^{2}+\mathrm{R}_{2}^{2}}}
$$

specific costs for rock disruption

$$
\mathrm{e}=\mathrm{c}_{1} \mathrm{~h}^{\mathrm{c}_{2}}
$$

auger performance

$$
Q=v_{s n} \pi R_{c}^{2}
$$

where $p_{n i}, p_{m}, p_{c}, p_{y i}, p_{0 i}, p_{e i}$ - pressure values at the pump outlet, the inlets of the hydraulic motor 6 and the hydraulic cylinder 5 , the throttle outlets, in the control systems of pumps 1 and 2, in the servo cylinders of the pumps; $z_{i}, x_{i}, y_{i}-$ coordinates of the position of pump regulators, adjustable throttles, differential pressure valves; $\omega_{m}, v_{s n}$ - shaft rotation speed of the hydraulic motor 6 and the feed of the 
auger $15 ; \gamma_{i}$ - angle of rotation of the pump face plates; $f_{0 i}, f_{e i}, f_{x i}, F_{7}$ - areas of throttles in pump regulators, the areas of spools of adjustable throttles, the area of pump pistons; $d_{c}, d_{p}, d_{y i}, d_{z}, d_{8}-$ diameters of the piston of the hydraulic cylinder 5 , differential pressure valves, pump regulators, the diameter of the contact circle of the pump pistons with the pump face; $i_{m i}$ - values of current in the windings of electromagnets; $k_{m i}, k_{4}, k_{1}-$ proportionality factors of electromagnet force of adjustable throttles, pressure sensor, the number of pistons in pumps; Le, Re- inductance and active resistance of electromagnet windings; $c_{z i}, c_{y i}-$ stiffness of springs of pump regulators and pressure difference valves; $T_{\mathrm{c}}, M_{m}$ - values of the reduced loads on the rod of the hydraulic cylinder 5 and the shaft of the hydraulic motor $6 ; \mu$ - flow rate through throttle and spool elements; $\rho$ - density of the working fluid; $l-$ arm action of servo cylinders of pumps; $I, I_{m}-$ moments of inertia of the pump faceplate and moving elements driven by the shaft of the hydraulic motor $6 ; I_{c}$ - inertia moment of the handle; $W_{n i}, W_{0}, W_{m}, W_{y i}, W_{c}, W_{e}$ - volumes of hydraulic lines at the pump outlet, in the pump regulators, at the inlet of the hydraulic motor 6 , at the outlet of the pressure drop valves, at the inlet to the hydraulic cylinder 5 , between the throttles and servo cylinders of the pumps; $n_{i}$ - number of revolutions of the pump shafts; $F_{k}\left(U_{p m}\right)$ - transfer function of the controller for the signal supplied to the amplifier 11; $F_{n}$ - transfer function of amplifiers; $F_{k 1}-$ transfer function of the controller for the signal transmitted to the amplifier $10 ; H_{z i}, H_{y i}$ - pre-compression springs of pump regulators and differential pressure valves; $m_{0}, m_{1}, m_{2}, m_{3}, m_{4}, m_{5} \quad$ - $\quad$ dependence coefficients of the resistance moment on faceplates of pumps on the feed and pressure values; $\beta_{p}$-reduced factor of pliability of the gas-liquid mixture; $\beta_{n}-$ reduced factor of rubber-metal pipelines and gasliquid mixture; $q_{m}$ - displacement of the hydraulic motor 6; $U_{1}, U_{2}$ - voltage values on the electromagnets of adjustable throttles 7, 16; $U_{a 1}, U_{a 2}$ - voltage values at the inputs of the amplifiers 10 and $11 ; E_{p 0}, E_{p}, E_{m p}(p)$ - modulus of the working fluid elasticity, the reduced modulus of elasticity of the gas-liquid mixture and rubber-metal pipelines; $\delta-$ wall thickness of the pipeline; $W_{f}$ - volume of liquid in the gas-liquid mixture at value of pressure $\mathrm{p} ; W_{a}-$ volume of gas in the gas-liquid mixture at atmospheric pressure, $C_{1}$ - parameter that depends on the properties of soil; $C_{2}$ - parameter that depends on the type of tool; $z$ - number of cutting blades of the tool; $R_{c}$ - pit diameter; $R_{1}$ - diameter of the auger base; $k_{n}$ - proportionality factor for the axial force of electromagnets.
The mathematical model equations (equations 1 to 27) were solved by using the Rosenbrock numerical method in MATLAB-Simulink environment with absolute accuracy of $\varepsilon_{a}=10^{-6}$ and relative accuracy of $\varepsilon_{6}=10^{-3}$.

The presence of several simultaneously operating regulators in the adaptive hydraulic system, the pliability of the working fluid and metal-rubber pipelines, the inertia of the load on the hydraulic motors, the friction forces in the regulators, in the hydraulic motors and on the actuating element can create unstable operating modes. A study of the influence of parameters $k_{p}$ and $\Delta T_{0}$ on the stability of the adaptive hydraulic system is carried out based on two pumps in the ranges of parameter changes of $k_{p}=$ $=(10 \ldots 1000) \cdot 10^{-7} \mathrm{~s}$ and $\Delta T_{0}=(0.025 \ldots 1.1) \mathrm{s}$. The research results are presented in Figure 3. The adaptive hydraulic system loses stability at values of $k_{p}<80 \cdot 10^{-7} \mathrm{~s}, \quad k_{p}>1000 \cdot 10^{-7} \mathrm{~s}$ and $\Delta T_{0}<0.025 \mathrm{~s}$, $\Delta T_{0}>0.11 \mathrm{~s}$. On the basis of the carried-out researches the area of admissible values of $k_{p}$ and $\Delta T_{0}$ is defined, at which steady work of adaptive hydraulic system is provided $k_{p}=(360 \ldots 800) \cdot 10^{-7} \mathrm{~s}$ and $\Delta T_{0}=$ $=(0.03 \ldots 0.094) \mathrm{s}$.

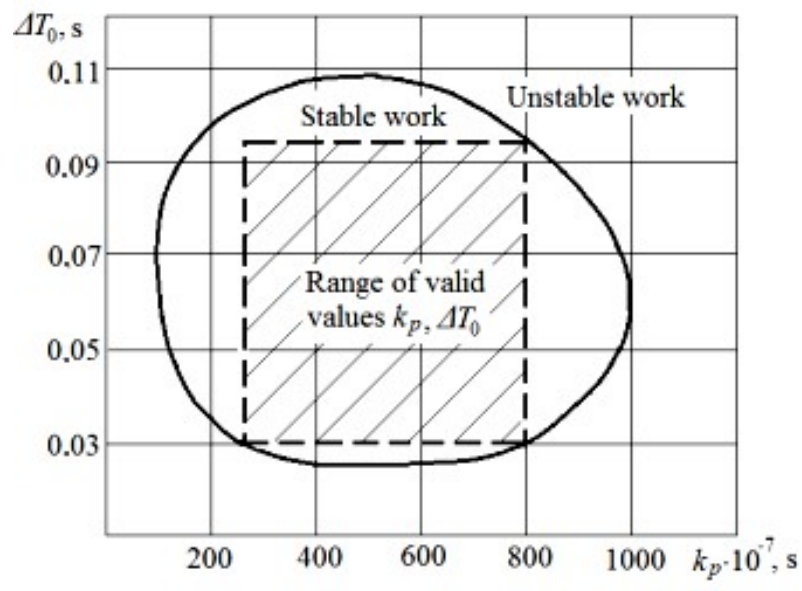

Fig. 3. Setting intervals for values $k \_p$ and $\Delta T \_0$ to ensure stable operation of the adaptive hydraulic system

A study of the influence of the parameters of the controller settings $k_{p}$ and $\Delta T_{0}$ the time of regulation $t_{p}$ and the re-adjustment value $\sigma$ according to the pressure in the adaptive hydraulic system with a step change in the load on the auger is carried out. In Figure 4(a), the influence of $\Delta T_{0}$ on $t_{p}$ is shown. The adjustment time $t_{p}$ varies from $3 \mathrm{~s}$ to $1 \mathrm{~s}$ when changing $k_{p}$ from $100 \cdot 10^{-7} \mathrm{~s}$ to $350 \cdot 10^{-7} \mathrm{~s}$ and increases from 1 to $3 \mathrm{~s}$ when increasing $k_{p}$ from $500 \cdot 10^{-7} \mathrm{~s}$ to $800 \cdot 10^{-7} \mathrm{~s}$ when settings of $\Delta T_{0}=0.08 \mathrm{~s}$.

In Figure 4(b), the influence of values $k_{p}$ and $\Delta T_{0}$ on the value of of re-adjustment $\sigma$ determined by the pressure $p_{m}$ at the inlet to the hydraulic motor is presented. When the value of $\Delta T_{0}=0.02 \mathrm{~s}$, the value 
of $\sigma$ increases above $40 \%$ when changing $k_{p}$ from $100 \cdot 10^{-7} \mathrm{~s}$ to $600 \cdot 10^{-7} \mathrm{~s}$. When the value of $\Delta T_{0}=0.08$ s, the value of $\sigma$ decreases from the values $\sigma=50 \%$ to $\sigma$ $=23 \%$ at increase of $k_{p}$ from $150 \cdot 10^{-7} \mathrm{~s}$ to $800 \cdot 10^{-7} \mathrm{~s}$. When the value of $\Delta T_{0}=0.1 \mathrm{~s}, \sigma$ decreases from $50 \%$ to $29 \%$ at $k_{p}=(400 \ldots .500) \cdot 10^{-7} \mathrm{~s}$ with further growth of $\sigma$ up to $42 \%$ at increase of $k_{p}$ from $500 \cdot 10^{-7} \mathrm{~s}$ to $800 \cdot 10^{-7} \mathrm{~s}$.

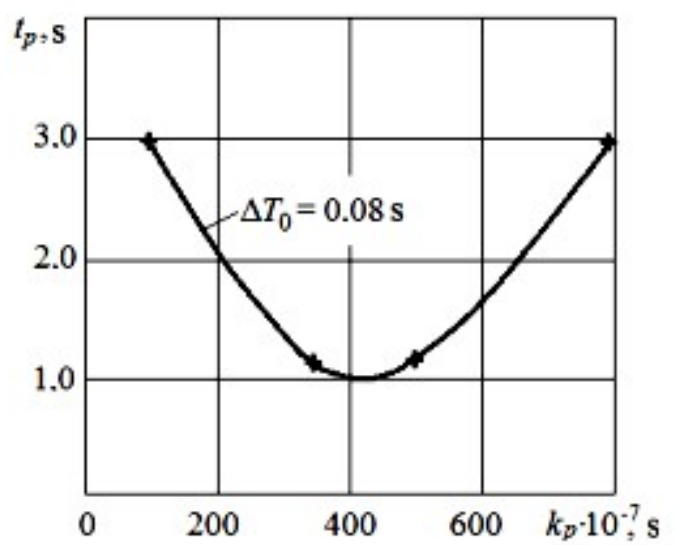

(a)

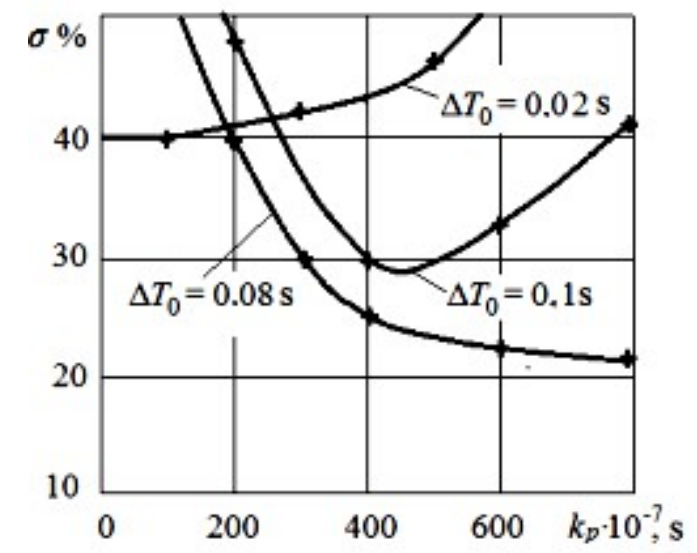

(b)

Fig. 4. Influence of values $\Delta T_{0}$ and $k_{p}$ on adjustment time $t_{p}$ (a) and the value of re-adjustment $\sigma$ (b)

During the operation of the adaptive hydraulic system for pit drilling operations, it is necessary to maintain a stable rotation speed $\omega_{m}$ of the hydraulic motor shaft, which actuates the auger. This is ensured by the presence of the throttle 7 and the differential pressure valve 8 in the adaptive hydraulic system (see Figure 1). The controller 9 provides a change in the feed rate $v_{c}$ according to a certain dependence, which is implemented in the program. The program uses the dependence of type $U_{a 2}==U_{0}-k_{0} U_{p m}$, where $U_{0}$ and $k_{0}$ are rates that vary depending on the mode of operation of the adaptive hydraulic system and the value of loads on the auger.
The static characteristic of an adaptive hydraulic system was defined as the dependence of $Q_{m}=f\left(p_{m}\right)$ and $Q_{c}=f\left(p_{m}\right)$. These dependences were determined by a mathematical model of adaptive hydraulic system. When changing the load torque $M_{m}$ on the shaft of the hydraulic motor 6 , the rotation speed of $\omega_{m}$ its shaft is maintained stable, and the feed rate $v_{s n}$ is reduced by a value determined by the algorithm of the controller 9. The value of the hydraulic motor shaft rotation speed $\omega_{m}$ value before the change of torque $M_{m}$ and after its increase at different torque values of $M_{m}$ was determined and the dependence $Q_{m}=f\left(p_{m}\right)$ was built up, where the value of $Q_{m}$ was defined as $Q_{m}=\frac{\omega_{m} q}{\eta}$. At the same time, the value of the feed rate $v_{s n}$ was used for determining the value of $Q_{c}$. The static characteristic of the adaptive hydraulic system is presented in Figure 5. For the characteristic of $Q_{m}=f\left(p_{m}\right)$, the error of flow rate stabilization $Q_{m}$ was determined at change of pressure $p_{m}$, which was calculated by the formula of $A=\frac{Q_{m}^{\max }-Q_{m}^{\min }}{Q_{m}^{\min }} \cdot 100 \%$, where $Q_{m}^{\max }, Q_{m}^{\min }$ - the maximum and minimum values of the flow rate arriving to the hydraulic motor at various values of pressure $p_{m}$.

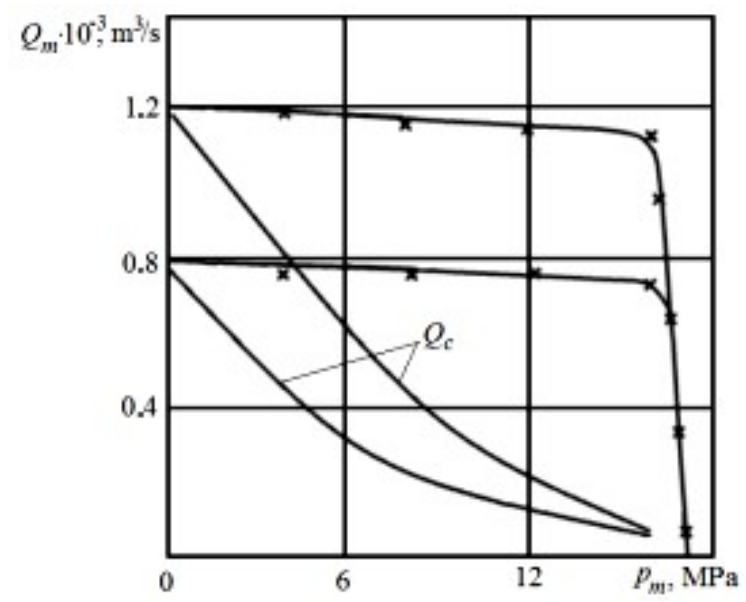

Fig. 5. Dependence of flow $Q_{m}$ to hydraulic motor and $Q_{c}$ to hydraulic cylinder on the value of pressure $p_{m}$ at the inlet to the hydraulic motor

The error of flow rate stabilization $Q_{m}$ does not exceed $8.6 \%$. When changing the flow rate to the hydraulic motor in the range of $Q_{c}=(0.15 \ldots 1.2) \cdot 10^{-3}$ $\mathrm{m}^{3} / \mathrm{s}$ and the pressure in the range of $p_{m}==(2 \ldots 16)$ $\mathrm{MPa}$.

In Figure 6, the working process calculated on mathematical models in adaptive hydraulic system at change of the resistance moment of $M_{m}$ on a shaft of the hydraulic motor 6 is presented. 


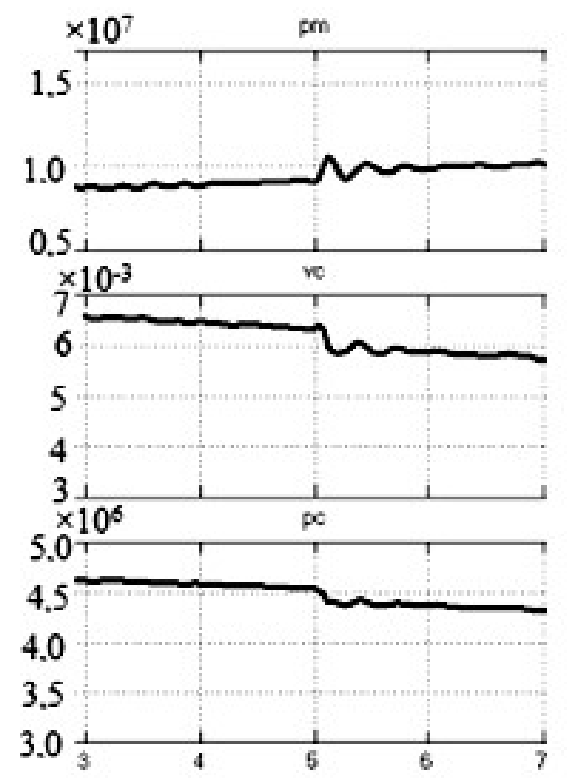

(a)

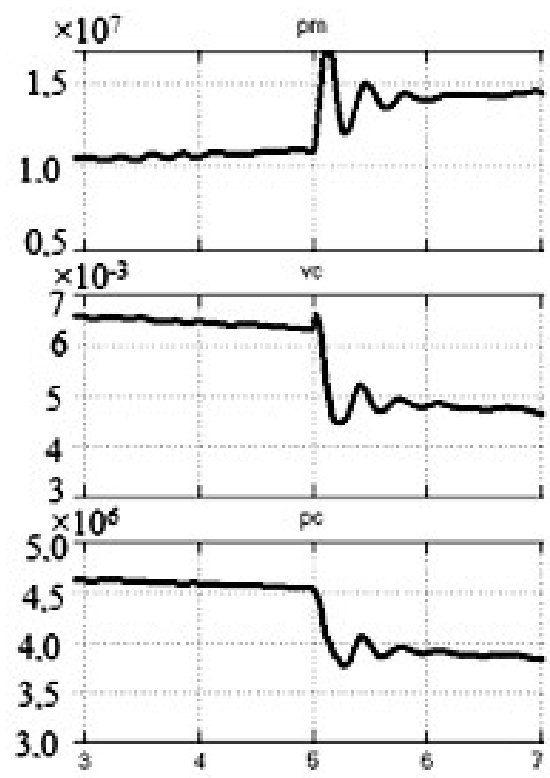

(b)

Fig. 6. Working process in the adaptive hydraulic system at change of the resistance moment on the shaft of the hydraulic motor $\Delta M_{m}=80 \mathrm{~N} \cdot \mathrm{m}(\mathrm{a}), \Delta M_{m}=300 \mathrm{~N} \cdot \mathrm{m}$ (b)

In Figure 7, the control algorithm for an adaptive hydraulic system is shown.

The algorithm provides automatic adjustment of two parameters for setting the adaptive hydraulic system:

- ensuring the ratio between the rotation speed of the auger $\omega_{m}$ and the feed of the auger $v_{c}$, at which the productivity of loose rock transportation exceeds the productivity of drilling. This ratio eliminates pinching of the auger during drilling.

- active pressure control of $p_{m}$ at the inlet to the hydraulic motor is carried out in order to limit the pressure of $p_{n 1}$ at the pump outlet and ensure uninterrupted drilling when soil properties are changed.

The algorithm works as follows:

1. The value of the auger rotation speed $\omega_{m}^{k p}$ is determined.

2. The value of rotation speed $\omega_{m}=\omega_{m}^{k p}$ of the hydraulic motor speed is set.

3. The critical value of the auger feed $v_{c}$ is determined by the formula $v_{s n}^{\prime}=\frac{\omega_{m}(1-\varphi) h_{b}}{2 \pi\left(1+k_{c} / k_{p}\right)}$.

4. In accordance with the determined value of $v_{s n}$, the value of the area of the throttle 7 is adjusted, which determines the flow rate $Q_{n 1}$ to and the rotation speed $\omega_{m}$ of the motor 6 .

5. The value of the area of the throttle 16 , which determines the flow rate $Q_{n 2}$ the value of feed $v_{s n}^{\prime}$ is adjusted.

6. The condition $v_{s n} \leq v_{s n}^{\prime}$ is checked.

7. The condition $p_{m} \leq p_{m}^{\max }$ is checked.

8. In the case of $p_{m} \geq p_{m}^{\max }$, due to the increase of external forces, acting on the auger during drilling, the feed rate value $v_{s n}$ is decreased.

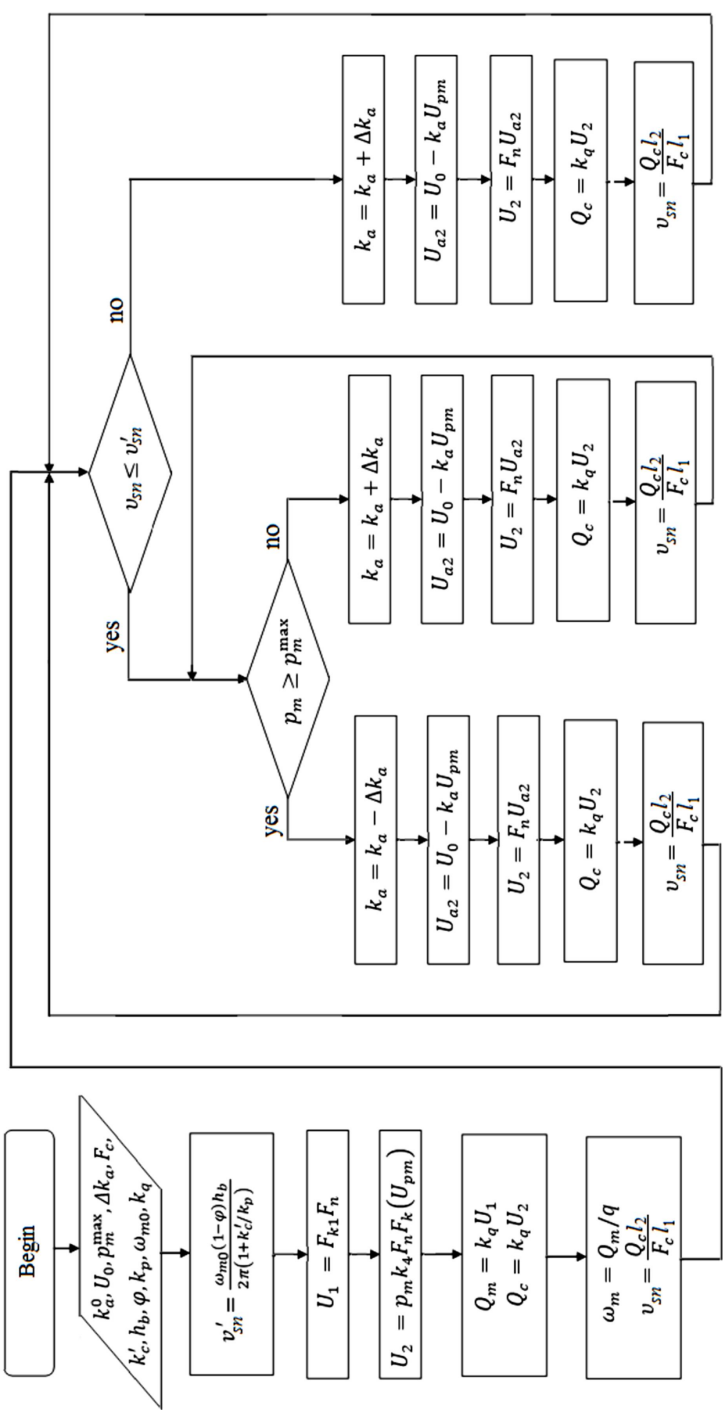

Fig. 7. Algorithm for an adaptive hydraulic system 
9. Reducing the auger feed $v_{s n}$ and, accordingly, the pressure at the pump outlet prevents the pump 1 from shutting down.

10. If the value of pressure $p_{m}$ decreases during drilling and the condition $p_{m}<p_{m}^{\max }$ is fulfilled, the feed rate $v_{s n}$ will increase, but the condition is provided.

According to the mathematical model, the possibility of using the values for the controller settings of $k_{p}=$ $400 \cdot 10^{-7}$ and $\Delta T_{0}=0.08 \mathrm{~s}$ is tested. The operation of the adaptive hydraulic system is stable, the transients are oscillating in nature $k=3 \ldots 4$. The adjustment time did not exceed $t_{p}=1.0 \mathrm{~s}$, and the value of readjustment $\sigma$ is less $30 \%$.

\section{CONCLUSIONS}

The proposed control algorithm of the adaptive hydraulic system provides such a ratio between the rotation speed of the auger and the value of its feed in the drilling process, in which the productivity of soil disruption with the auger does not exceed the productivity of transporting loose soil from the drilled depth, which ensures uninterrupted operation of the machine in the working cycle. Depending on loading, the auger feed value changes under condition of not exceeding admissible pressure value in the hydraulic system. With the setting of the controller $k_{p}=400 \cdot 10^{-7}$ $\mathrm{s}, \Delta T_{0}=0.08 \mathrm{~s}$, the adjustment time in the hydraulic system does not exceed $t_{p}=1.0 \mathrm{~s}$, the value of readjustment on pressure $\sigma \leq 30 \%$, and the error of stabilization of the flow rate to the hydraulic motor $A \leq$ $8.6 \%$.

\section{REFERENCES}

1. Burennikov Y, Kozlov L, Pyliavets V, Piontkevich $\mathrm{O}$, (2017), O Mechatronics hydraulic drive with regulator based on artificial neural network, IOP Conf. Ser.: Mater. Sci. Eng. 209012071.

2. Kozlov L., (2015), Scientific foundations for designing the systems of manipulator hydraulic drives with an adaptive neural network-based controllers for mobile working machines (National Technical University of Ukraine «Kyiv Polytechnic Institute» of the Ministry of Education of Ukraine Kyiv).

3. Karakozov A, Yushkov I, Popova M, Parfenyuk S, Sagaydak I, (2011), Drilling equipment. Hydraulic systems of drilling rigs and machines (DonNTU Donetsk).

4. Budagromash Machine-Building Company LLC. Manufacturer of excavators, loaders and crane drilling machines Product catalogue www.budagromash.com.

5. Kozlov L., (2013), Digital PD controller for dynamic correction of the differential component coefficient for a mechatronic hydraulic system
Tehnomus journal: Proceedings of the XVIIth International Conference "New Technologies and Products in Machine Manufacturing Technologies"Suceava-Romania, 120-125.

6. Kozlov L., (2011), Energy-saving mechatronic drive of the manipulator, The Bulletin of the Polytechnic Institute Iasi-Romania LVII (LXI), 3, 231-239.

7. Sidorenko VS, Grishchenko VI, Rakulenko SV, Poleshkin MS, (2017), Adaptive hydraulic drive with volumetric control of the tool feed of the technological machine, Bulletin of Donetsk State Technical University, 2, 88-98.

8. Kazachenko GV, Basalay GA, Nagorskiy AV, Shuldova SG, Yarmolinskiy VK, (2013), Research of auger drilling process. Part 2 - Performance and methodology for calculating its characteristics, Mining mechanics and mechanical engineering, 3, 53-60.

9. Kazachenko GV, Nagorskiy AV, Basalay GA, (2012), Research of auger drilling process. Part 1 Formation of mathematical model of the work flow in steady-state drilling, Mining mechanics and mechanical engineering, 3, 65-74.

10. Kozlov L, Buriennikov Y, Piliavets V, Kotyk S, (2020), Adaptive hydraulic system, Patent 144036 Ukraine IPC E02F 9/22 F15B 13/06 No. u202002212 $165 \mathrm{p}$.

11. Strutynsky V, Hurzhii A, Kozlov L, (2019), Determination of static equilibrium conditions of a mobile terrestrial robotic complex, Naukovyi Visnyk Natsionalnoho Hirnychoho Universytetu, 5, 79-96. 12.Petrov O, Kozlov L, Lozinskiy D, Piontkevych O, (2020), Improvement of the Hydraulic Units Design Based on CFD Modeling Mechanical Engineering book series (LNME) XXII, 653-660.

13.Kozlov L, Polishchuk L, Korinenko M, Horbatiuk M, Orazalieva S, Ussatova O, (2019), Experimental research characteristics of counterbalance valve for hydraulic drive control system of mobile machine, Przeglad Elektrotechniczny, 4, 104-109.

14.Kozlov L, Bogachuk V, Bilichenko V, Tovkach A, Gromaszek K, Sundetov S, (2018), Determining of the optimal parameters for a mechatronic hydraulic drive, Proc. SPIE, Photonics Applications in Astronomy, Communications, Industry, and HighEnergy Physics Experiments, 10808, 61-71.

15.Petrov O, Slabkyi A, Vishtak I, Kozlov L, (2020), Mathematical Modeling of the Operating Process in LS Hydraulic Drive Using MatLab GUI Tools, DSMIE 2020: Advances in Design, Simulation and Manufacturing III, Lecture Notes in Mechanical Engineering, 1-11, 52-62.

Received: February 26, 2021 / Accepted: December 20, 2021 / Paper available online: December 25, 2021 (C) International Journal of Modern Manufacturing Technologies 